\title{
Analysis of Energy and Power Parameters on the Extruding of Copper Installation Conform with Prechamber
}

\author{
Yuriy V. Gorokhov*, \\ Sergey V. Belyaev, Ivan Yu. Gubanov, \\ Igor V. Uskov and Alexandr G. Ivanov \\ Siberian Federal University \\ 79 Svobodny, Krasnoyarsk, 660041, Russia
}

The object of the calculation served as a real process of continuous extrusion of copper profiles on the installation Conform equipped with a set of pressing tool prechamber at the factory for processing non-ferrous metals in the city of Kamensk-Uralsk. To calculate the length of the split container, which should provide on its moving surface friction force sufficient to extrude the metal from the forehearth in a point matrix, the torque on the drive wheel and the electric motor power, used a methodology based on the determination of the total compression force, which was proposed by I.L. Perlin. These equations are characterized by simplicity and ease of use in technical and technological design of the metal extrusion process method Conform with prechamber.

Keywords: Conform machine, pre-chamber, continuous extrusion, energy-power calculation, the active friction.

Citation: Gorokhov Yu.V., Belyaev S.V., Gubanov I.Yu., Uskov I.V., Ivanov A.G. Analysis of energy and power parameters on the extruding of copper installation Conform with prechamber, J. Sib. Fed. Univ. Eng. technol., 2018, 11(4), 481-487. DOI: $10.17516 / 1999-494 X-0071$.

(c) Siberian Federal University. All rights reserved

* Corresponding author E-mail address: 160949@list.ru 


\title{
Анализ энергосиловых параметров экструдирования меди на установке «Конформ» с форкамерой
}

\author{
Ю.В. Горохов, С.В. Беляев, \\ И.Ю. Губанов, И.В. Усков, А.Г. Иванов \\ Сибирский федеральный университет \\ Россия, 660041, Красноярск, пр. Свободньій, 79
}

\begin{abstract}
Объектом расчета послужил реальный технологический процесс непрерывного экструдирования медных профилей на установке «Конформ», оснащенной комплектом прессового инструмента с форкамерой на заводе по обработке ияветных металлов в городе Каменск-Уральский. Для расчета длинь разъемного контейнера, которая должна обеспечить на его подвижной поверхности силу трения, достаточную для экструдирования металла из форкамеры 6 очко матрицы, крутящего момента на приводном колесе и мощности электродвигателя, использована методика, основанная на определении полного усилия прессования, которая была предложена И.Л. Перлиным. Полученные уравнения отличаются простотой и удобством использования при техническом и технологическом проектировании процесса экструдирования металла способом «Конформ» с применением форкамер.
\end{abstract}

Ключевые слова: машина «Конформ», форкамера, непрерывная экструзия, энергосиловой расчет, активное трение.

\section{Введение}

Размеры ранних конструкций матриц для установки «Конформ» не выходили за пределы ширины ручья колеса, что в свою очередь ограничивало габариты прессуемых профилей. Прессование с расширяющейся у матрицы камерой, разработанной в последнее время, позволило увеличить габариты пресс-изделий относительно исходной заготовки [1]. Использование установок «Конформ» с форкамерами различной формы и размеров значительно расширяет сортамент не только сплошных, но и полых пресс-изделий. По этому принципу фирмой Babcock (США) разработан способ Конформ/Конклад для экструдирования полых профилей с неподвижной иглой, которая может быть заменена двигающимся сердечником для его непрерывного плакирования [2].

В установке «Конформ» экструзия профиля в очко матрицы и заполнение металлом форкамеры происходят за счет сил контактного трения заготовки с подвижной поверхностью разъемного контейнера в виде ручья в приводном колесе. Неподвижную часть контейнера составляет сегментная вставка с форкамерой и выступом, перекрывающим поперечное сечение ручья. Прутковая заготовка задается в контейнер, захватывается ручьем вращающегося колеса, продвигается до упора в выступ вставки, выдавливается в форкамеру и экструдируется в очко матрицы [3].

\section{Методика определения силы экструдирования}

На рис. 1 изображена схема непрерывной экструзии металла способом «Конформ» с применением такой форкамеры. Прутковая заготовка 3 задается в ручей 2 приводного колеса $1 \mathrm{c}$ помощью прижимного ролика 4 , продвигается до выступа матрицедержателя 8 , выдавливается 
через канал и заполняет расширяющуюся форкамеру. На выходе из форкамеры установлена матрица 5, в калибрующее отверстие которой экструдруется пресс-изделие 6.

К настоящему времени несколько зарубежных фирм [4-6] производят установки с подобной схемой прессования. Одна из таких модификаций промышленных установок «Конформ» приведена на рис. 2.

Для осуществления устойчивого процесса непрерывной экструзии профиля с использованием форкамеры необходимо выполнение следующего условия:

$$
\mathrm{T}_{\mathrm{a}}=\mathrm{T}_{\mathrm{K}}+\mathrm{P}_{\mathrm{B}}+\mathrm{P}_{\phi}+\mathrm{P}_{\ni}+\mathrm{T}_{\phi}+\mathrm{T}_{\mathrm{M}}
$$

где $\mathrm{T}_{\mathrm{a}}$ - активная сила трения на контакте заготовки с канавкой колеса; $\mathrm{T}_{\mathrm{\kappa}}$ - сила на преодоление трения по поверхности неподвижной части контейнера (вставка и выступ матрицедержателя); $\mathrm{P}_{\text {в }}$ с сила на выдавливание металла из контейнера в форкамеру; $\mathrm{P}_{\phi}-$ сила на заполнение форкамеры; $\mathrm{P}_{э}$ - сила на экструзию профиля в очко матрицы; $\mathrm{T}_{\phi}$ - сила на

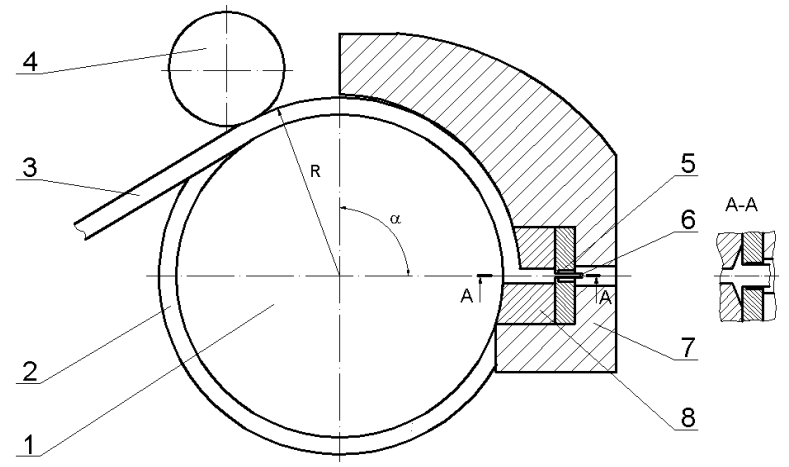

Рис. 1. Схема установки «Конформ» с расширяющейся форкамерой: 1 - приводное колесо; 2 - кольцевая канавка (ручей колеса); 3 - прутковая заготовка; 4 - прижимной ролик; 5 - матрица; 6 - пресс-изделие; 7 - башмак; 8 - корпус форкамеры с выступом матрицедержателя

Fig. 1. Scheme of installation Conform with the expanding prechamber: 1 -drive wheel; 2 - an annular groove (wheel rim); 3 - bar stock; 4 - pressure roller; 5 -die; 6 -a press product; 7 - shoe; 8 - the body of the prechamber with a projection of the die holder

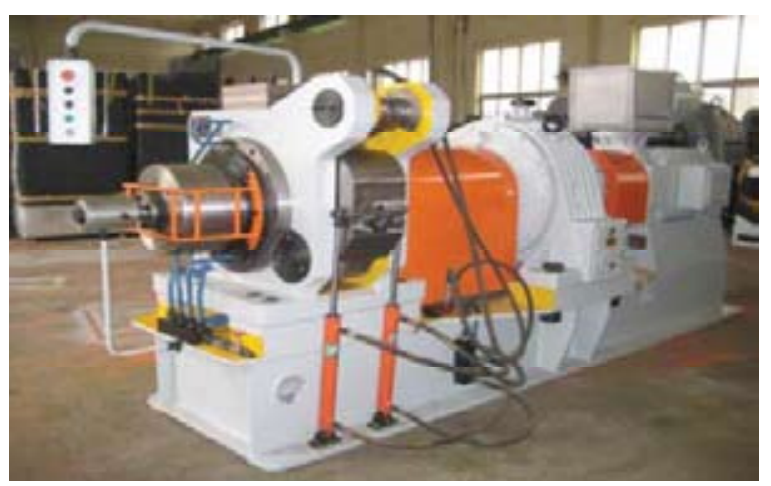

Рис. 2. Общий вид установки «Конформ» фирмы Dalian Konform Technical Co., Ltd [ 6 ]

Fig. 2. General view of the installation of the Conform of Dalian Conform Technical Co., Ltd [6] 
преодоление трения по поверхности форкамеры; $\mathrm{T}_{\mathrm{m}}$ - сила на преодоление трения по поверхности матрицы [7-9].

Определим силу на преодоление трения по поверхности неподвижной части контейнера:

$$
\mathrm{T}_{\mathrm{K}}=\sigma_{\mathrm{s}} \cdot \mu \cdot \mathrm{F}_{\mathrm{B}}
$$

где $\sigma_{\mathrm{s}}-$ сопротивление деформации при заданной температуре; $\mu$-показатель трения; $\mathrm{F}_{\mathrm{B}}-$ площадь контакта заготовки с неподвижной частью контейнера [10].

Для вычисления $\mathrm{P}_{\text {в }}$ и $\mathrm{P}_{\phi}$ воспользуемся формулой и диаграммой В.И. Залесского, приведенной в справочнике под редакцией Е.И. Семенова [11], определяющими силу высадки головки стержня:

$$
\begin{aligned}
& \mathrm{P}_{\mathrm{B}}=\sigma_{\mathrm{s}} \cdot \mathrm{k}_{1} \cdot \mathrm{F}_{\mathrm{\kappa}}, \\
& \mathrm{P}_{\phi}=\sigma_{\mathrm{s}} \cdot \mathrm{k}_{2} \cdot \mathrm{F}_{\phi},
\end{aligned}
$$

где $\mathrm{k}_{1}, \mathrm{k}_{2}$ - коэффициенты, величина которых зависит от отношения высоты высаживаемой головки к размеру поперечного сечения стержня и находится в интервале от 1,2 до 6,0 при отношении указанных размеров 1,8 и 0,2 соответственно; $\mathrm{F}_{\mathrm{k}}$ - площадь поперечного сечения канала между контейнером и форкамерой; $\mathrm{F}_{\phi}$ - площадь поперечного сечения форкамеры на зеркале матрицы.

Определим силу экструдирования профиля в очко матрицы:

$$
\mathrm{P}_{\ni}=\Pi \cdot \sigma_{\mathrm{s}} \cdot \ln \lambda \cdot \mathrm{F}_{\phi}
$$

где $\lambda$ - коэффициент вытяжки; п - коэффициент угла матрицы, по данным И.Л. Перлина [8] для плоских матриц п $=1,36$.

Сила на преодоление трения по поверхности форкамеры

$$
\mathrm{T}_{\phi}=\sigma_{\mathrm{s}} \cdot \mu \cdot \mathrm{F}_{\text {п. }},
$$

где $\mathrm{F}_{\text {п.ф }}$ - площадь контакта заготовки с боковой поверхностью форкамеры.

Сила на преодоление трения по поверхности матрицы

$$
\mathrm{T}_{\mathrm{M}}=\sigma_{\mathrm{s}} \cdot \mu \cdot \mathrm{F}_{\mathrm{M}}
$$

где $\mathrm{F}_{\mathrm{m}}$ - площадь контакта заготовки с боковой поверхностью матрицы.

\section{Определение энергосиловых параметров прессования медной шины}

Для проверки предложенной методики приведем пример расчета силы прессования при экструдировании медной шины $8 \times 50$ мм на установке ««Конформ» 400» с форкамерой, имеющейся на Каменск-Уральском заводе по обработке цветных металлов [12].

Расчет силы на преодоление трения по поверхности неподвижной части контейнера проведем по среднему значению $\sigma_{\mathrm{s}}$. При этом температуру металла на входе и выходе из контейнера примем 20 и $450{ }^{\circ} \mathrm{C}$ соответственно. Коэффициент трения 0,3, ширина вставки 20 мм, длина 100 мм. Форма и размеры сечения ручья колеса изображены на рис. 3. 


$$
\mathrm{T}_{\mathrm{K}}=0,5 \cdot(230+180) \cdot 0,3 \cdot\left(20 \cdot 100+1020+0,5 \cdot 3,14 \cdot 10^{2}\right)=72272 \mathrm{H} .
$$

Силу на выдавливание металла из контейнера в форкамеру найдем по формуле (3):

$$
\mathrm{P}_{\mathrm{B}}=180 \cdot 2,2 \cdot 400=158400 \mathrm{H} .
$$

Сила на заполнение форкамеры:

$$
\mathrm{P}_{\phi}=180 \cdot 1800=324000 \mathrm{H}
$$

Сила на экструзию профиля в очко матрицы из форкамеры:

$$
\mathrm{P}_{\ni}=1,36 \cdot 180 \cdot 1,5 \cdot 1800=660960 \mathrm{H} .
$$

Силу на преодоление трения по поверхности форкамеры рассчитаем исходя из границ деформационной зоны на макрошлифе темплета (рис. 4), при этом показатель трения $\mu$ достигает значения, равного 1:

$$
\mathrm{T}_{\phi}=180 \cdot 23 \cdot(24+50) \cdot 2=612720 \mathrm{H}
$$

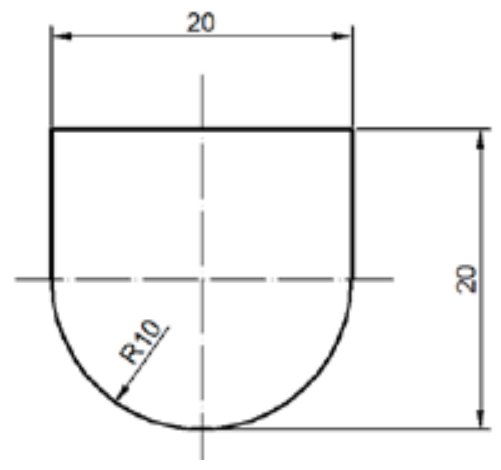

Рис. 3. Форма и размеры сечения ручья колеса установки ««Конформ» 400»

Fig. 3. The shape and dimensions of the cross section of the wheel of the "Conform 400" installation

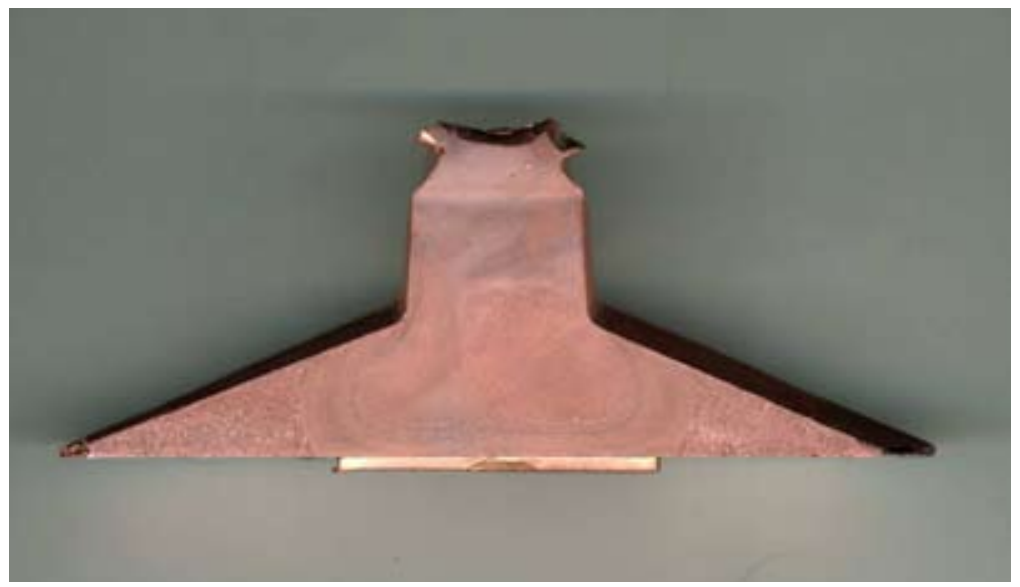

Рис. 4. Макрошлиф темплета, полученного при экструдировании медной шины

Fig. 4. Macro polishing of the temperature pattern obtained by extruding a copper bus

$$
-485-
$$


Сила на преодоление трения по поверхности матрицы:

$$
\mathrm{T}_{\mathrm{M}}=180 \cdot 0,3 \cdot 58 \cdot 2 \cdot 4=25056 \mathrm{H}
$$

Таким образом, полная сила, необходимая для экструзии медной шины $8 \times 50$ мм, составит:

$$
\begin{aligned}
& \mathrm{T}_{\mathrm{a}}=72272+158400+324000+660960+612720+25056= \\
& =1853408 \mathrm{H}=1,85 \mathrm{MH}(185,34 \mathrm{Tc}) .
\end{aligned}
$$

Экспериментальное значение силы прессования при экструдировании этой шины на установке «Конформ» Каменск-Уральского завода ОЦМ составило 1,95 МН, что показывает хорошую сходимость расчетных результатов с практически измеренными в ходе прессования значениями.

\section{Выводы}

Предложенная методика расчета силы прессования соответствует практическим результатам при прессовании с форкамерой медной шины, поэтому данная методика может использоваться инженерами и конструкторами при проектировании технологических процессов непрерывного прессования методом «Конформ», конструктивных параметров оборудования и прессового инструмента.

\section{Список литературы}

[1] Локшин М.З., Шамраев В.Н., Авдеев В.В., Богатов В.Ю. Современные способы непрерывного прессования труб, профилей и проволоки. Технология легких сплавов, 1992, (10), 60-65 [Lokshin M.Z., Shamraev V.N., Avdeev V.V., Bogatov V.Y. Modern methods of continuous extrusion of pipes, profiles and wire. Technology of light alloys, 1992, (10), 60-65. (in Russian)]

[2] Manninen T., Katajarinne T., Ramsay P. Analysis of Flash formation in continuous rotary extrusion of copper. Journal of Materials Processing Technology, 2006, 177, 600-603.

[3] Bryant A., Dixon W. Isothermal Extrusion. Light Metal Age, 1999, (3), 8-36.

[4] Проспект фирмы Holton Machinery Ltd. (Великобритания), 1986. 29 с. [Prospect of company Holton Machinery Ltd. (Great Britain), 1986. 29 p. (in Russian)]

[5] Проспект фирмы Babcock Wire Equipment Ltd. (Великобритания), 1987. 27 с. [Prospect of company Babcock Wire Equipment Ltd. (UK), 1987, 27, p. (in Russian)]

[6] Проспект фирмы Dalian Konform Technical Co., Ltd. (Китай), 2008. 22 с. [Prospect of company Dalian Konform Technical Co., Ltd. (China), 2008, 22, p. (in Russian)]

[7] Данченко В.Н., Миленин А.А., Головко А.Н. Производство профилей из алюминиевых сплавов. Теория и технология. Днепропетровск: Системные технологии, 2002. 439 с. [Danchenko V.N., Milenin A.A. Golovko A.N. Profiles production of aluminum alloys. Theory and technology. Dnepropetrovsk, System Technology, 2002. 439 p. (in Russian)]

[8] Горохов Ю.В., Шеркунов В.Г., Довженко Н.Н., Беляев С.В., Довженко И.Н. Основы проектирования прочессов непрерывного прессования металлов. Красноярск: Сиб. федер. ун-т, 2013. 268 c. [Gorokhov Y.V., Sherkunov V.G., Dovzhenko N.N., Belyaev S.V., Dovzhenko I.N. Fundamentals of process of continuous extrusion of metals. Krasnoyarsk, Sib. Feder. University Press, 2013. 268 p. (in Russian)] 
[9] Перлин И.Л., Райтбарг Л.Х. Теория прессования металлов. М.: Металлургия, 1975. 447 с. [Perlin I.L., Raytbarg L.H. Theory of metal pressing. M., Metallurgy, 1975. 447 p. (in Russian)]

[10] Щерба В.Н. Прессование алюминиевых сплавов. М.: Интермет инжиниринг, 2001. 768 с. [Szczerba V.N. Pressing of aluminum alloys. M., Intermet Engineering, 2001. 768 p. (in Russian)]

[11] Корнилов В.Н. Непрерывное прессование со сваркой алюминиевых сплавов. Красноярск: Изд-во пед. ин-та, 1993. 216 с. [Kornilov V.N. Continuous extrusion with welding of aluminum alloys. Krasnoyarsk, Izd ped. Inst, 1993. 216 p. (in Russian)]

[12] Семенов Е.И. Ковка и штамповка. Справочник в 4-х томах: т. 2. Горячая объемная штамповка, 1986. 592 c. [Semenov E.I. Forging and Stamping. Reference in 4 volumes:. Vol. 2. Hot forging, 1986, 592 p. (in Russian)]

[13] Горохов Ю.В., Солопко И.В., Суслов В.П.. Расчет минимальной длины контейнера при непрерывном прессовании «Конформ»., Цветные металль, 2010, (10), 61-63. [Gorokhov J.V., Solopko I.V., Suslov V.P. Calculation of the minimum length of the container while continuously pressing Conform. Non-ferrous metals, 2010, (10), 61-63. (in Russian)]

[14] Мочалин И.В., Горохов Ю.В., Беляев С.В., Губанов И.Ю. Экструдирование медных шин на установке «Конформ» с форкамерой. Цветные металль, 2016, (5), 75-78. [Mochalin I.V., Gorokhov Yu.V., Belyaev S.V., Gubanov I.Y. Extrusion copper busbars Conform to install prechamber. Non-ferrous metals, 2016 (5), 75-78. (in Russian)] 